\title{
A report on experience with an automatic blood counting machine
}

\author{
A. E. GREEN, V. L. MidDleton, K. G. PRENTis, \\ AND A. G. SIGNY
}

From the Group Laboratory, St Stephen's Hospital, London

SYNOPSIS Experience after 18 months' work with the SMA-4 system of multiple analysis for routine haematology is described, as well as the modifications to the machine which have been made for smoother operation.

The routine work load of this haematology laboratory consists of investigations of anaemia and 'routine' counts on all patients admitted to the hospital. The SMA-4 machine for estimating haemoglobin, haematocrit, white cell count, and red cell count has been in routine use since 1 May 1967. Most of the work is put through the machine, the remainder being done by hand from capillary blood samples and from very urgent specimens. Stained blood films are examined from every specimen.

\section{STANDARDIZATION AND QUALITY CONTROL}

The machine is phased between 11 and 12 in the morning and the run starts at about $1.00 \mathrm{pm}$. For use as a standard and in quality control, $15 \mathrm{ml}$ of blood is taken from a donor. The methods used to assay this sample are also the methods used for capillary blood and urgent tests: haemoglobin by the cyanmethaemoglobin method; white cell and red cell counts by electronic particle counter; and haematocrit by microcentrifugation. These methods are standardized by international or other standards and are further controlled when numerical results are compared with an opinion on a blood smear. This sample is then used to standardize and to

Received for publication 25 November 1968. phase the SMA-4 and is inserted as every twentieth specimen throughout the day as a quality control. Table I shows the reproducibility of the 'manual' methods.

\section{MECHANICAL RELIABILITY OF THE SMA-4}

The machine is electronically very stable. The main problems are fibrin clots in tubing and leaking of reagents at unions which require the constant presence of a technician with experience of the machine. A small number of spares, eg, a flow cell, wash valve, and manifold tubing have to be kept despite their cost. Only occasionally will a fault occur which is difficult to repair.

\section{CHANGES MADE TO THE ORIGINAL MODEL}

Because of difficulties experienced with the manifold which had to be replaced too frequently and at considerable cost, an additional pump was added to take the larger tubes. This arrangement has lengthened the life of the manifold from one or two weeks to four weeks; phasing is smoother and the stability, especially of the white cell counts, is improved.

A sampler plate which will hold routine seques-

TABLE I

REPRODUCIBILITY OF MANUAL METHODS IN GROUPS OF 14 ESTIMATIONS

Estimation Results ( $\pm 1 S D)$

\begin{tabular}{lcccc} 
& Sample 1 & Sample 2 & Sample 3 & Sample 4 \\
\hline Hb & $14.06 \pm 0.04$ & $8.6 \pm 0.02$ & $14.47 \pm 0.14$ & $15 \cdot 1 \pm 0.36$ \\
pcv & $41 \pm 1 \cdot 2$ & $30.3 \pm 1.8$ & $44.4 \pm 1 \cdot 2$ & $46.2 \pm 0.8$ \\
wbc & $4.5 \pm 0.8$ & $14.7 \pm 0.6$ & $7.3 \pm 0.9$ & $9.8 \pm 1.0$
\end{tabular}


trene tubes has been devised. This eliminates transfer of blood to cups, reduces preparation time and so avoids possible clerical errors.

\section{PRESENT STATUS OF EACH CHANNEL}

Acceptance of each of the SMA-4 channels depends on the following four parameters.

1 LINEARITY Dilutions of blood prepared in its own plasma were estimated and the results plotted against the calculated results.

2 REPRODUCIBILITY A large sample of blood from one donor was split into $2.5 \mathrm{ml}$ aliquots and estimated seven times on the SMA-4. The aliquots from any one patient were not estimated consecutively, so that the effect of such factors as carry over would be included as in routine practice.

3 CORRELATION Results from the SMA-4 are compared with those from standard techniques.

4 STABILITY Because temporal variation may be a problem in a routine clinical laboratory, aliquots of a specimen of blood were fed into the SMA-4 and the hand method routines at different times throughout the working day. The results are com- pared with the results obtained under trial conditions In all these tests the aliquots carried a code number. and could be identified only by the person controlling the trials and not by individual operators.

\section{RESULTS}

HAEMOGLOBIN CHANNEL The cyanmethaemoglobin method is used with a solution containing potassiums ferricyanide, potassium dihydrogenphosphate, potas $\overrightarrow{0}$ sium cyanide, and Weyoc (an anionic detergent).

1 Linearity (Fig. 1) This is good but shows the problem of obtaining accurate dilution of whole blood.

2 Reproducibility (Table II) This is good.

TABLE II

REPRODUCIBILITY OF HB ESTIMATION DONE BY SMA-4 SEVEN TIMES

Hb Reading ( $\pm 1 S D)$

$13.9 \pm 0.3$

$8 \cdot 4 \pm 0.2$

$14 \cdot 6 \pm 0.3$

$15 \cdot 6 \pm 0.2$

$14 \cdot 5 \pm 0 \cdot 4$

3 Correlation (Fig. 2) Correlation also is good 4 Stability (Fig. 3) This shows a close agreement

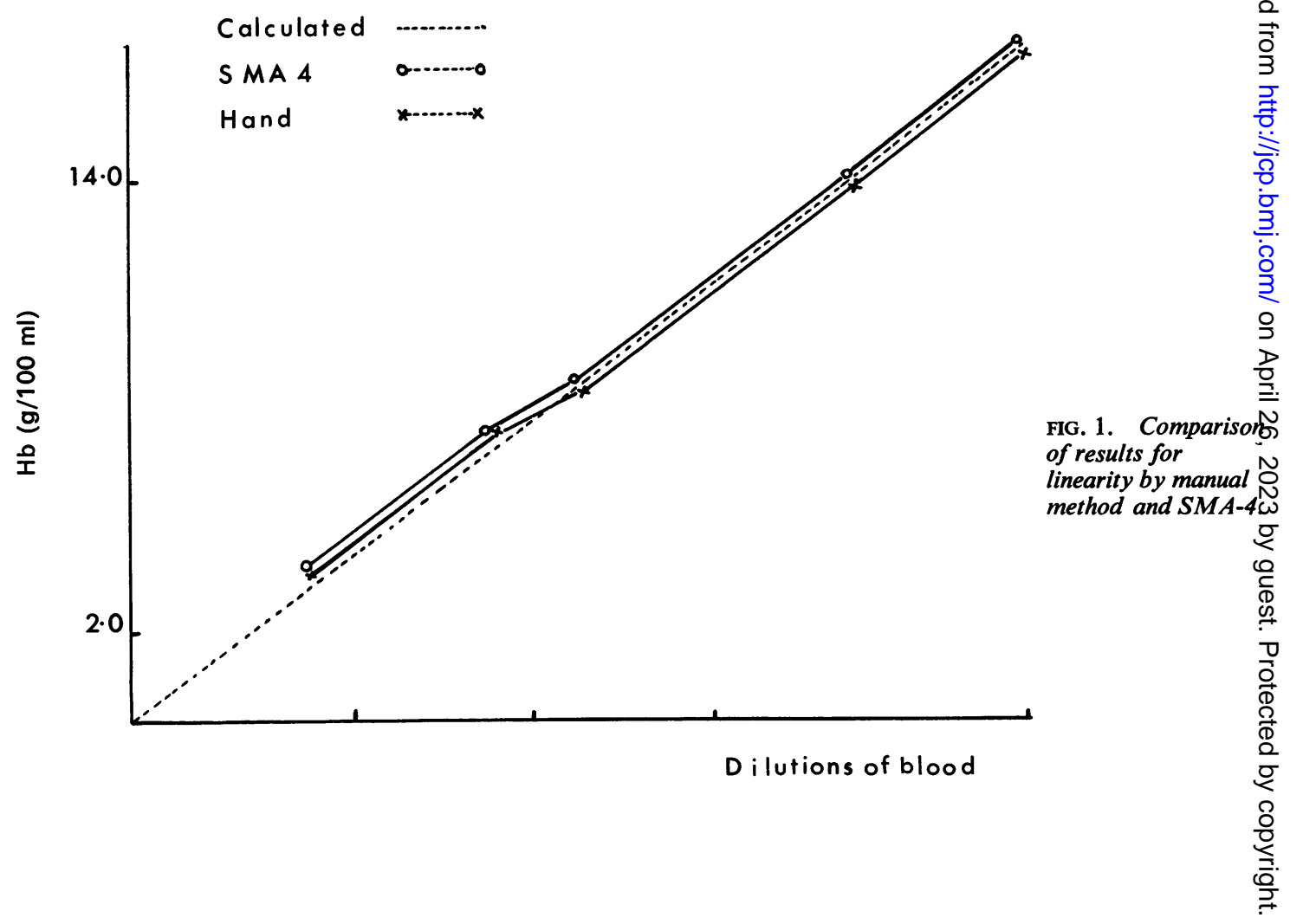




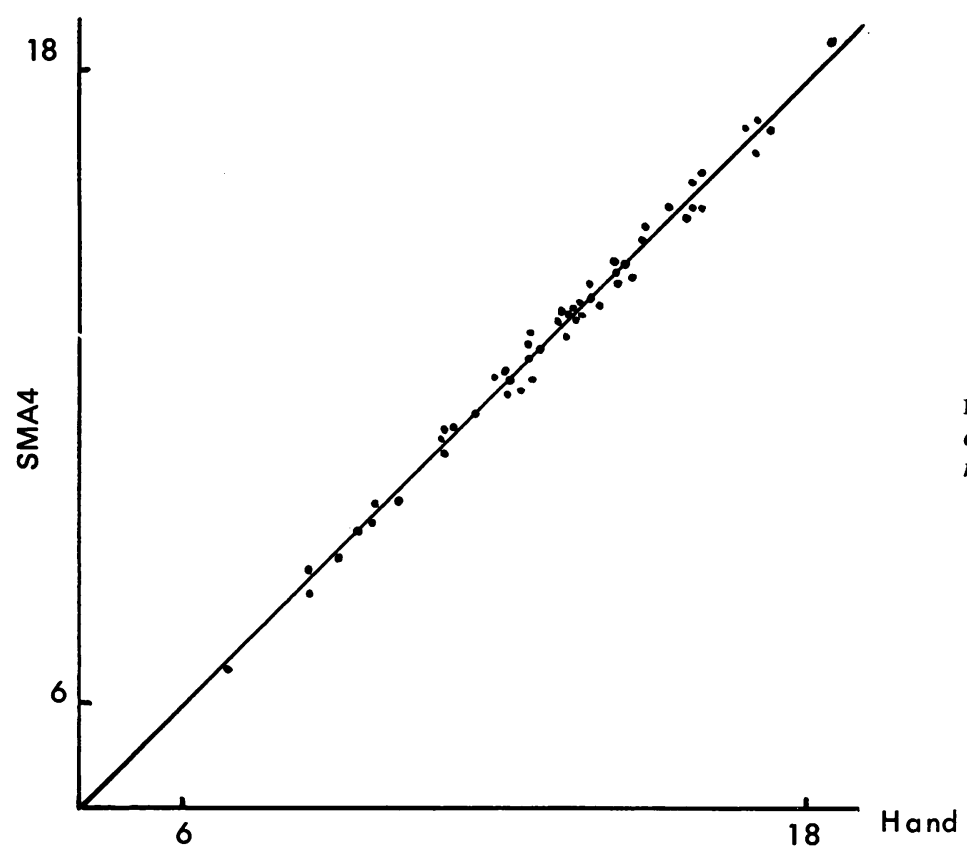

FIG. 2. Results for haemoglobin correlation estimates by the manual method and the SMA-4.

FIG. 3. Haemoglobin stability determined by hand and SMA-4 under trial and routine conditions. 


\section{PCV}

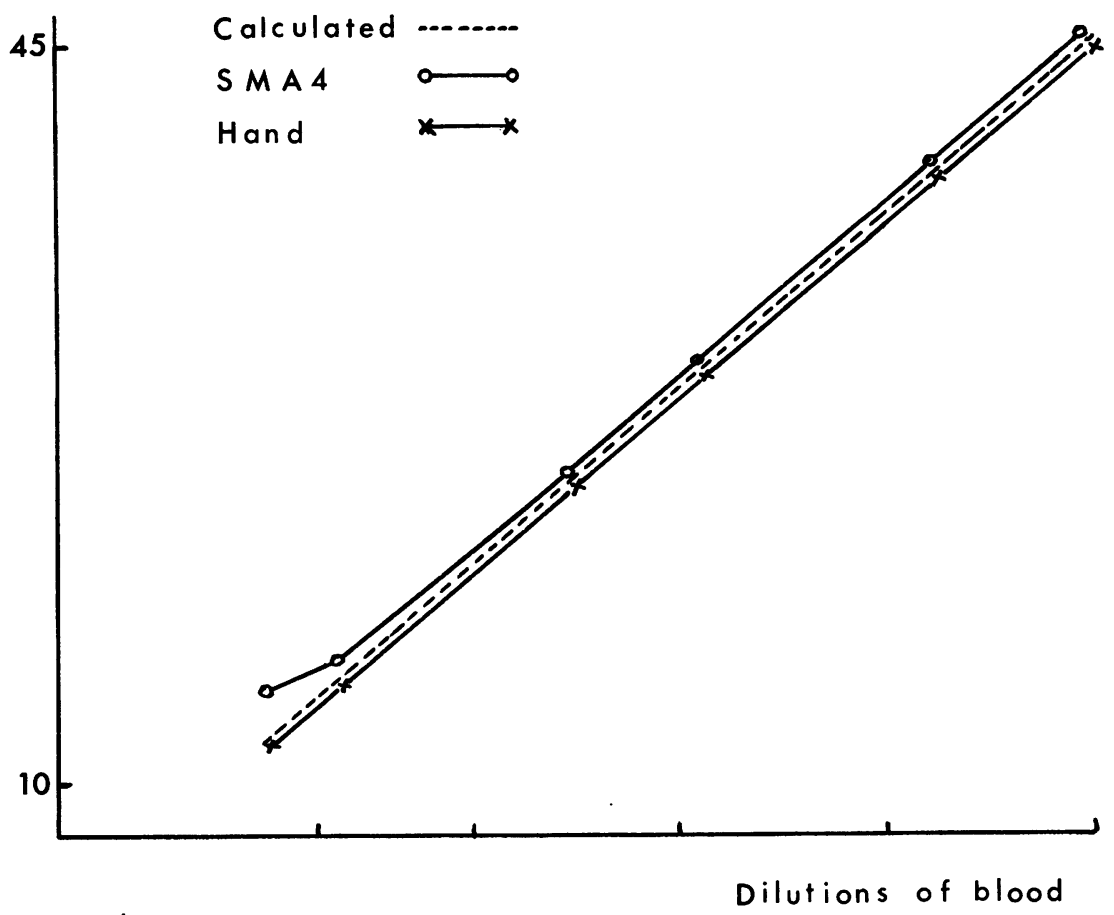

FIGS. 4 AND 5.

Linearity for packed cell volume in two samples: Fig. 4, sample 1 , and Fig. 5, sample 2.

FIG. 4.
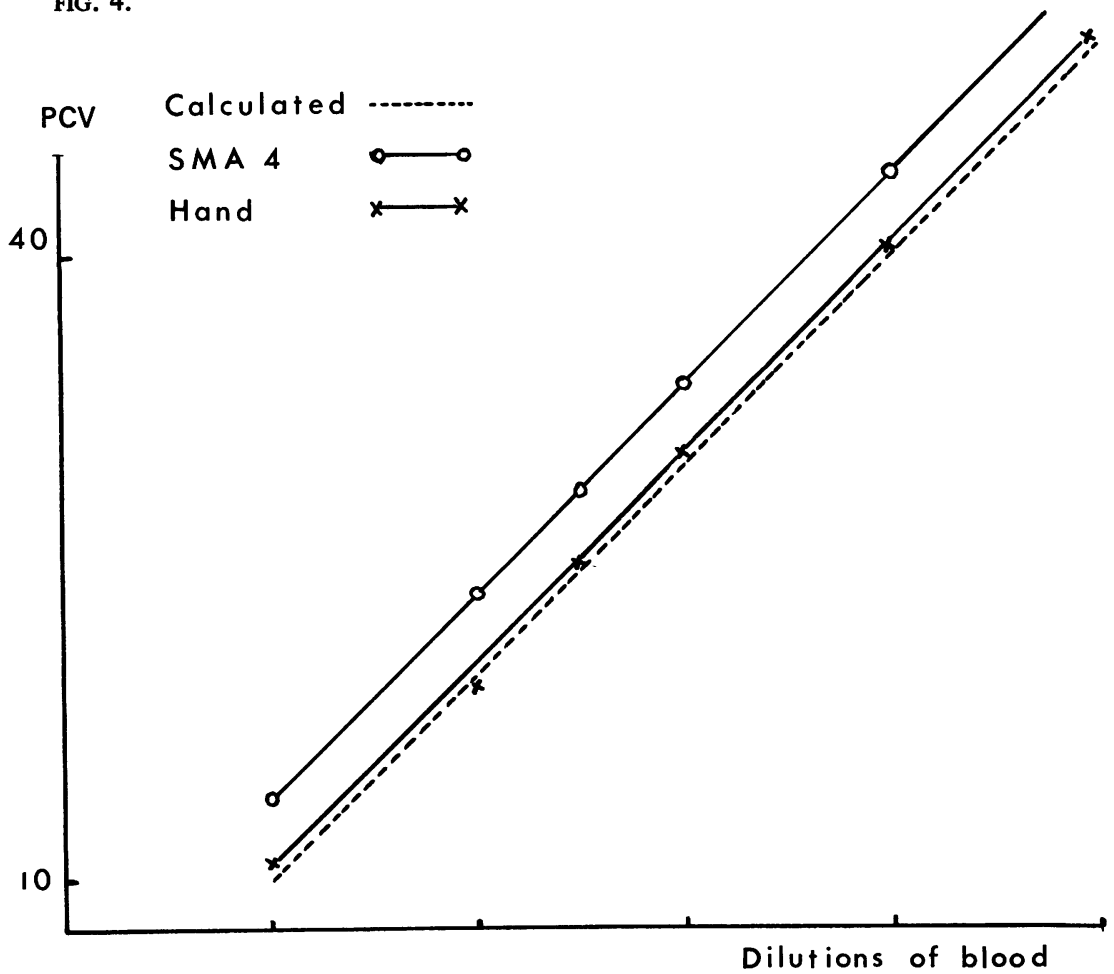

FIG. 5 . 
between the methods under both trial and routine conditions.

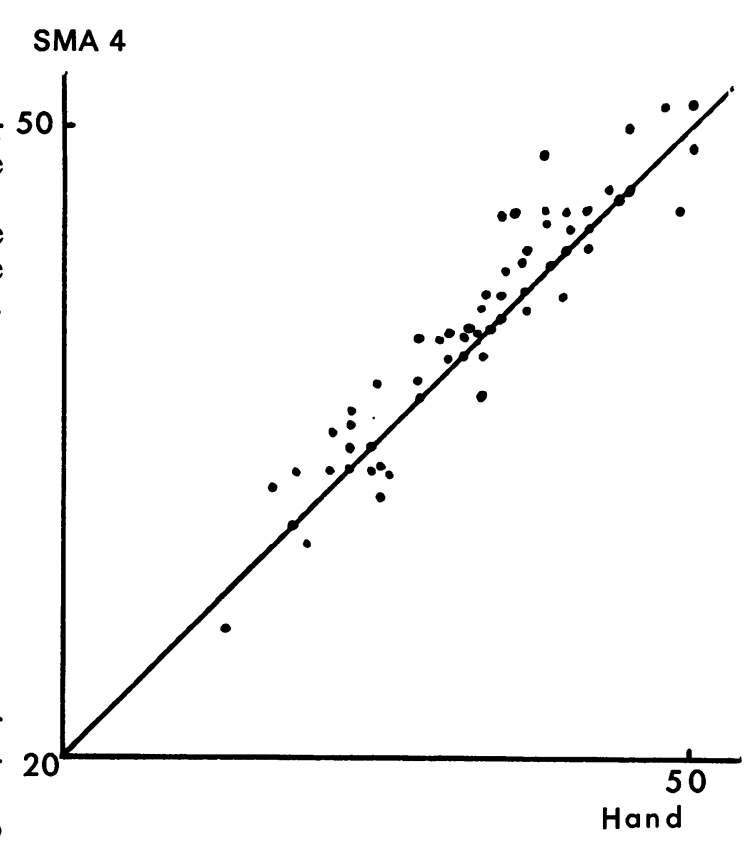

HAEMATOCRIT CHANNEL Two potassium chloride solutions are used to set the upper and lower 50 . ranges on the SMA-4 as results are not linear on one setting (Kernen, Wurzel, and Okada, 1961).

1 Linearity (Figs. 4 and 5) The linearity of the results is good but it will be seen that one sample (Fig. 5) gives uniformly higher results than expected.

2 Reproducibility (Table III) This is good.

TABLE III

REPRODUCIBILITY OF HAEMATOCRIT DONE BY SMA-4 PCV Readings ( $\pm 1 S D)$

$$
\begin{aligned}
& 40.1 \pm 0.6 \\
& 31.9 \pm 0.02 \\
& 42.8 \pm 0.04 \\
& 46.3 \pm 1.8 \\
& 41.1 \pm 0.6
\end{aligned}
$$

3 Correlation (Fig. 6) There is a tendency for the SMA-4 to give higher results than the microcentrifuge method.

4 Stability (Fig. 7) Stability is good but also shows the tendency for results to be higher by SMA-4.

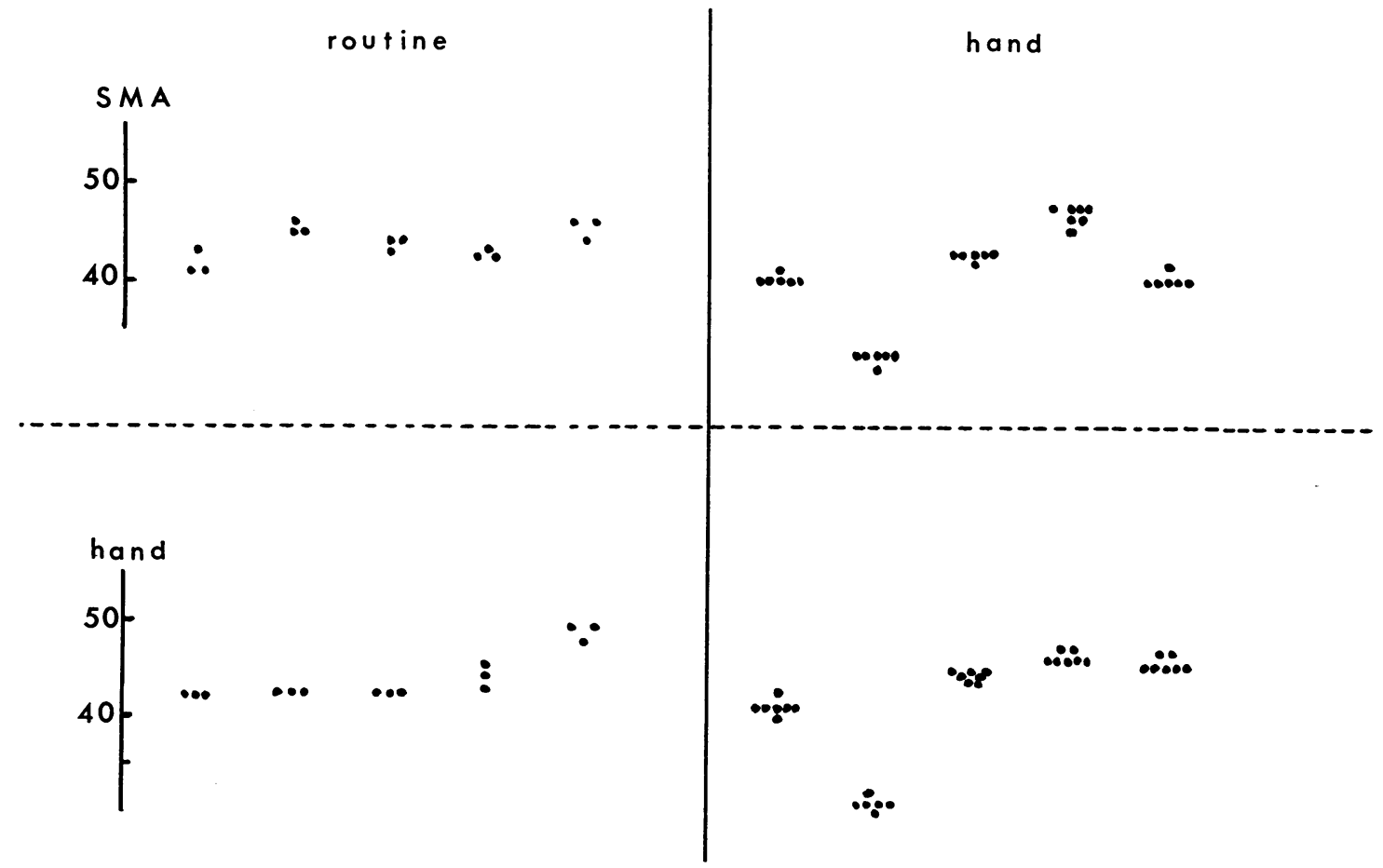

FIG. 7. Comparison of results for stability of packed cell volume estimations obtained by hand and the SMA-4 under routine conditions. 
MEAN CORPUSCULAR HAEMOGLOBIN CONCENTRATION (MCHC) This was calculated on all specimens and was repeated using a microcentrifuge haematocrit whenever the MCHC did not correlate with the opinion on the film. The number of discrepancies has been reduced since two pumps were used (Table IV). At present about $2 \frac{1}{2} \%$ are erroneous, but most 'fail safe', ie, the SMA-4 haematocrit causes the MCHC to appear low and yet haemoglobinization of red cells is normal and results using a microcentrifuge give a normal MCHC. A small percentage of results do not 'fail safe', ie, an abnormal degree of haemoglobinization would be regarded as normal. In almost all cases the haemoglobin would, of course, be low in these cases and this would therefore initiate further investigation.

\section{TABLE IV}

INCIDENCE OF ERRORS IN HAEMATOCRIT ESTIMATION DONE BY SMA-4

\begin{tabular}{lc} 
& No. of Errors \\
\hline$A$ Single pump & \\
Number of consecutive estimations & 2,391 \\
Number of errors & $107(4.5 \%)$ \\
Number of errors 'failing safe' & 99 \\
Number of errors not 'failing safe' & $8(0.3 \%)$ \\
& \\
$B$ Two pumns & 2,568 \\
Number of consecutive estimations & $69(2.7 \%)$ \\
Number of errors & 67 \\
Number of errors 'failing safe' & $2(0.08 \%)$ \\
Number of errors not 'failing safe' &
\end{tabular}

\section{SMA4}

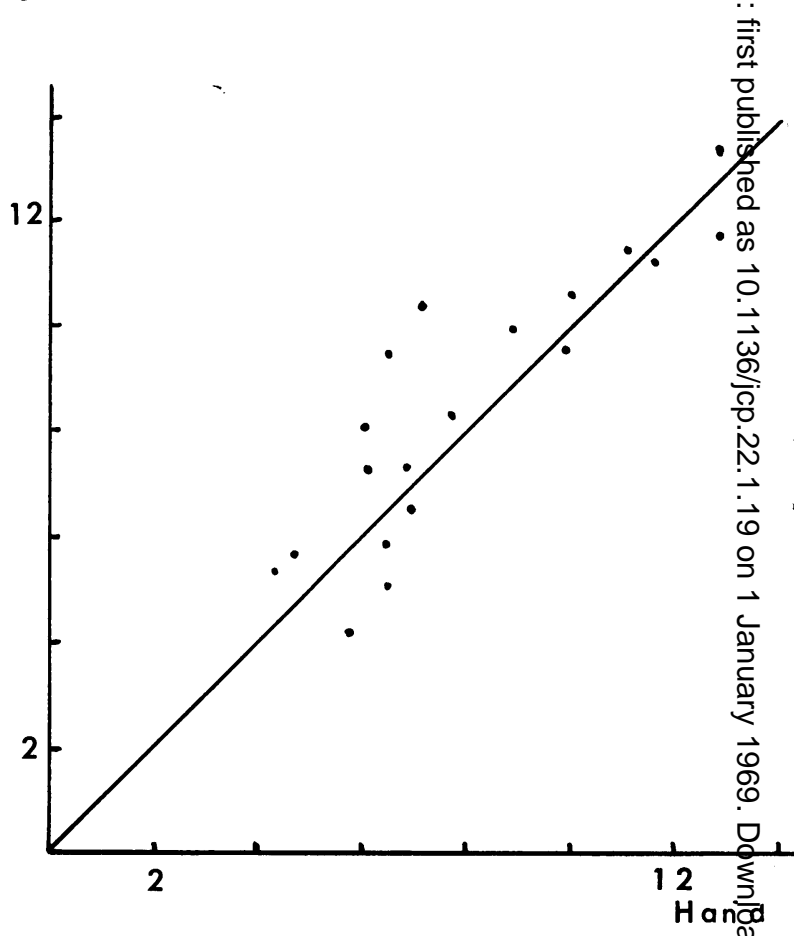

FIG. 9. Correlation for white cell count determined byo hand and by SMA-4.

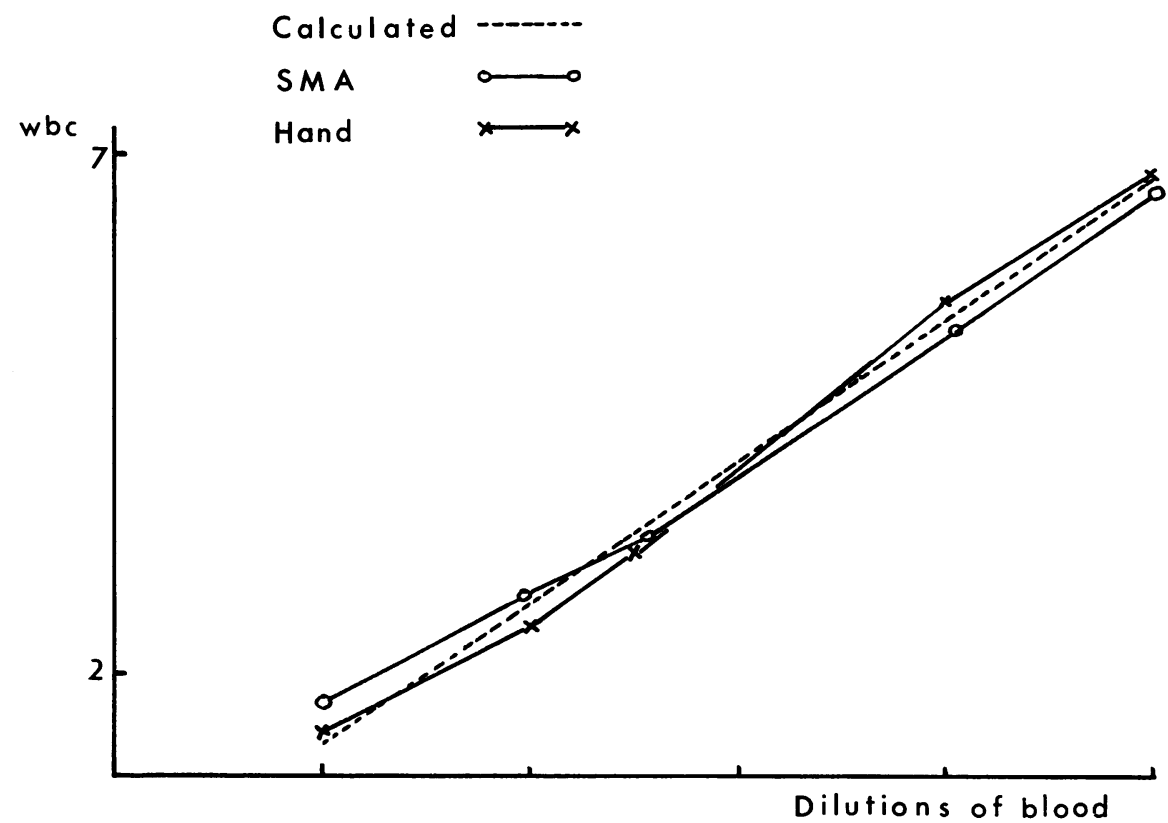

FIG. 8. Linearity for white cell count determined by hand and by $S M A-4$. 
WHITE CELl COUNTING CHANNEL The diluent used is $3 \%$ glacial acetic acid with Weyoc.

1 Linearity (Fig. 8) This is good.

2 Reproducibility (Table $V$ ) This is acceptable but not as good as with other channels.

TABLE V

REPRODUCIBILITY OF WBC ESTIMATED BY SMA-4

Results $( \pm 1 S D)$

$$
\begin{gathered}
3.3 \pm 0.08 \\
15.6 \pm 0.6 \\
6.2 \pm 0.2 \\
8.6 \pm 0.86 \\
3.7 \pm 0.4
\end{gathered}
$$

3 Correlation (Fig. 9) This shows a scatter greater than with other channels but within acceptable limits.

4 Stability (Fig. 10) This demonstrates the greater reproducibility of SMA-4 results under routine conditions and the phenomenon of greater accuracy when the 'trial' conditions are known to the operator.

The filter in the line needs to be changed about twice a week or a false bubble pattern will appear. The flow cell life is about six months and is rather expensive to replace.

RED CELL COUNTING CHANNEL This measured linearity and correlation.

1 Linearity (Fig. 11) Allowing for the difficulty in achieving accurate dilution of whole blood, it shows a slight falling in sensitivity of the SMA-4 with lower counts.

2 Correlation (Fig. 12) This is good. Although slightly higher values are given by SMA-4 they are within acceptable limits.

\section{CRITIQUE}

The rise in the number of requests in haematology in most laboratories is so great that mechanization and ultimately automation is becoming urgently

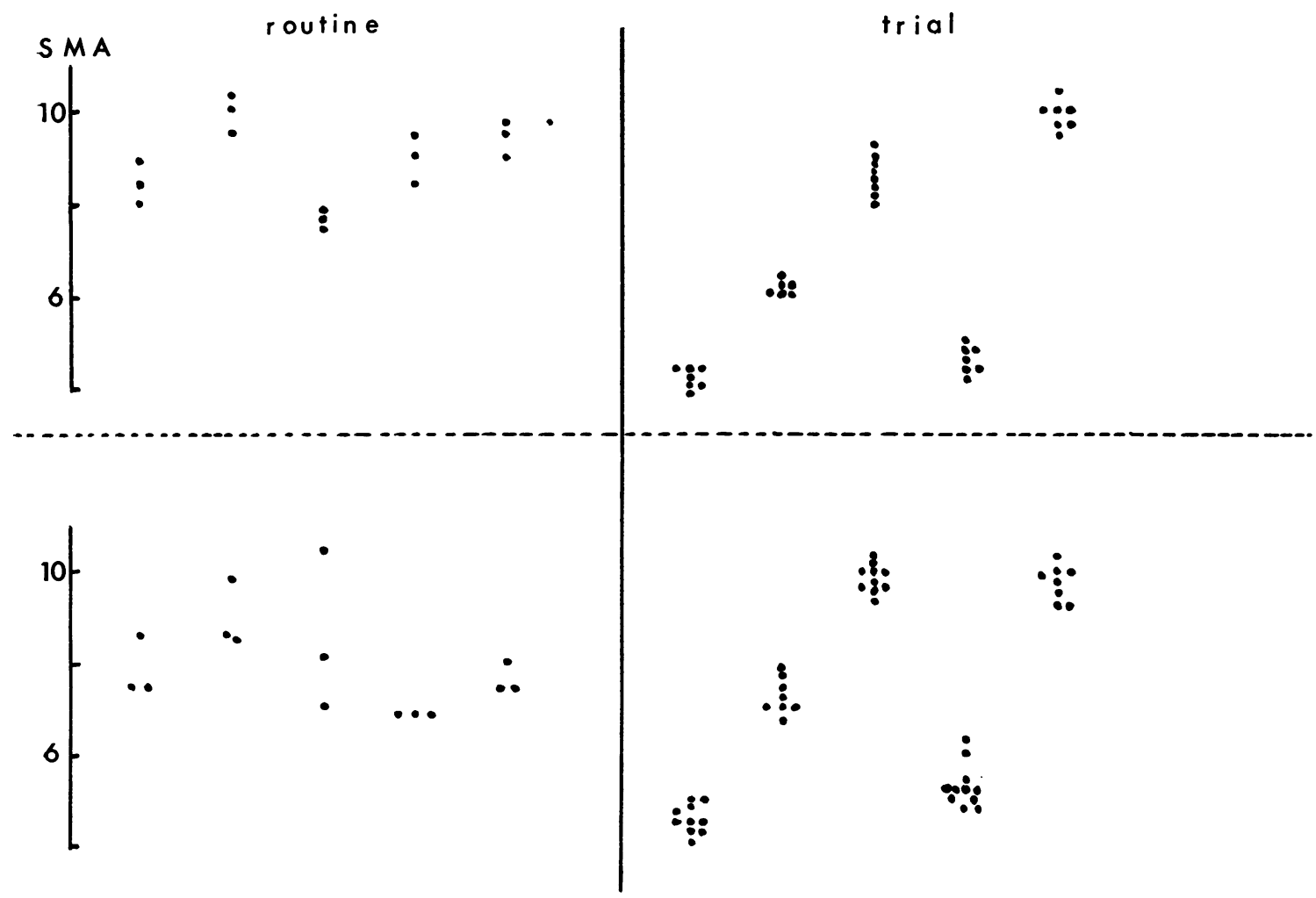

FIG. 10. Stability of results for white cell count determined by hand and by SMA-4 under routine and trial conditions. 


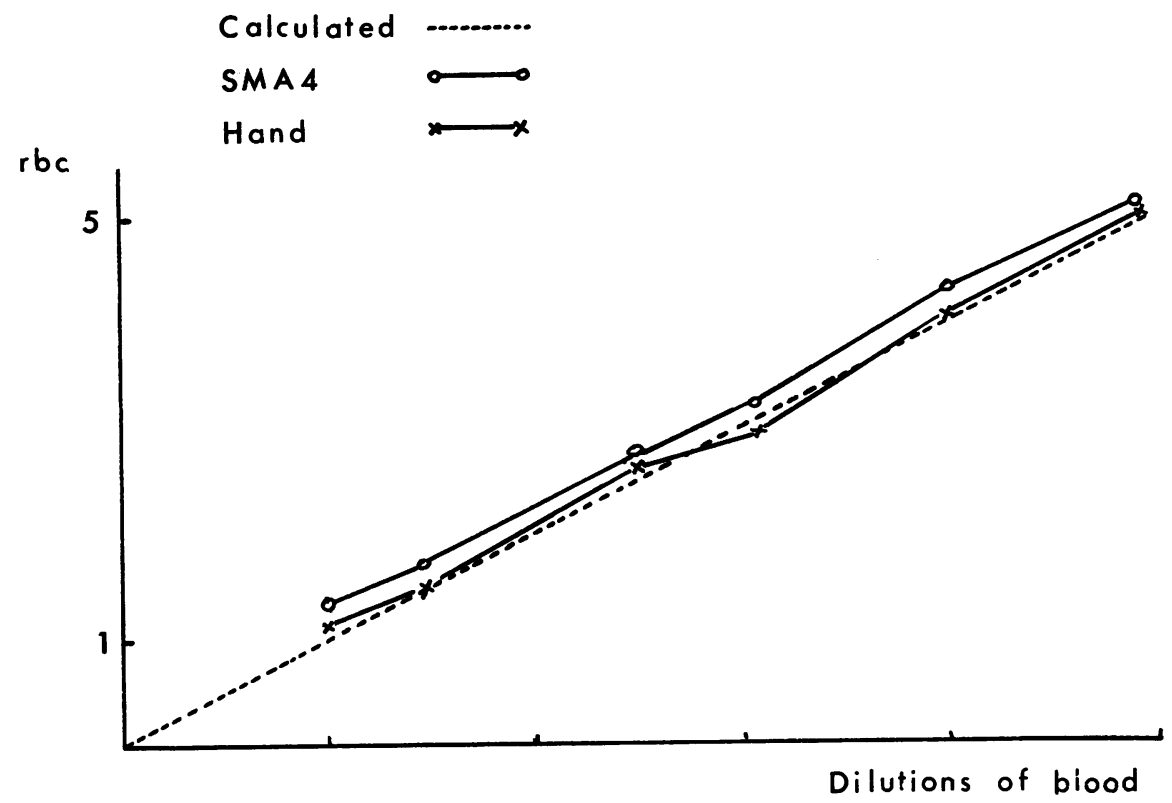

FIG. 11 .

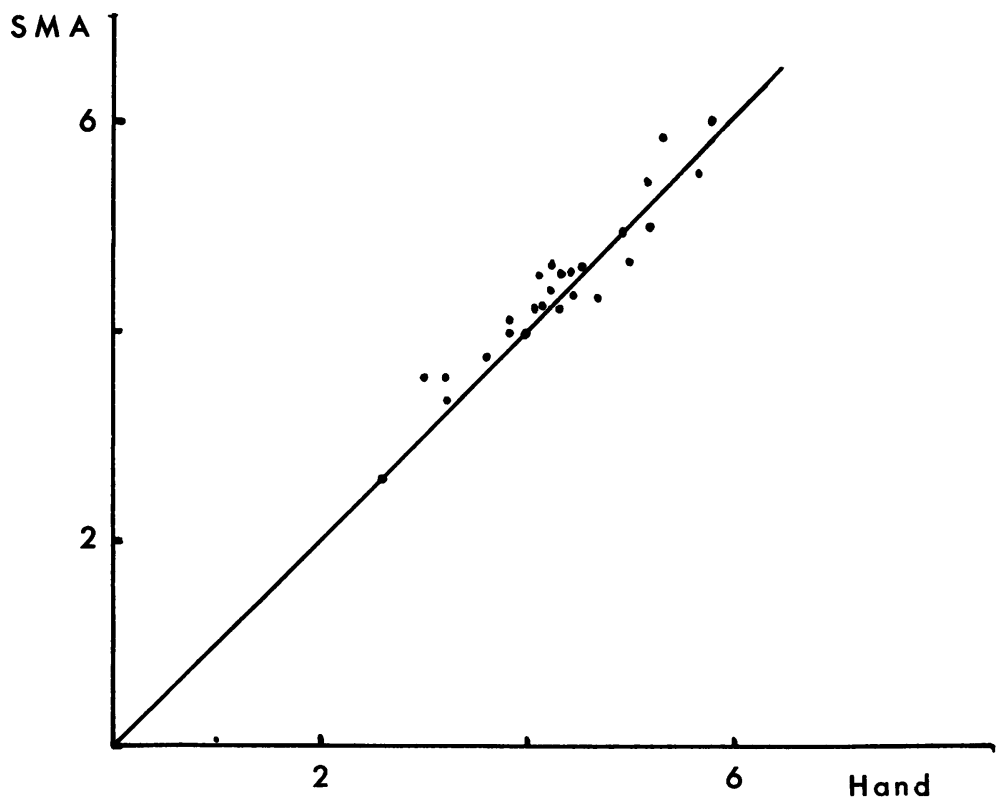

FIGS. 11 AND 12. Results for linearity (Fig. 11) and correlation $\overline{0}$ (Fig. 12) for red blood cells by hand and by SMA-4.

FIG. 12 .

necessary. The SMA-4 is an excellent machine to meet the demand. The results are accurate and correlate well with standard manual methods and opinions on blood films. The system has mechanized sampling and can be modified to link directly to computer or print-out system.

In the practice of clinical haematology we regard the screening of blood films as essential for many 
reasons and, therefore, do not regard the minor inaccuracy rate in the haematocrit results as invalidating the whole SMA-4 system.

However, we have certain criticisms. There should be an easy conversion system for data acquisition and computer linking.

Greater output from the SMA-4 as the number of requests rises can be achieved only by increasing the working day of the machine. This may have to be done by working the SMA-4 on a shift system.

Machine minders tend to become tired and it is essential, therefore, to vary the work of operators by allowing them to alternate with the special work of the haematology department which is found to attract many technicians.

In order not to miss the occasional undiagnosed haematological abnormality and to check the occasional erroneous result, especially on the haematocrit line of the SMA-4, there is an urgent need to increase the output of stained films and the speed of reporting on them.

\section{REFERENCE}

Kernen, J. A., Wurzel, H., and Okada, R. (1961), J. Lab. clin. Med., 57, 635 . 